IZA DP No. 6976

Leadership at School:

Does the Gender of Siblings Matter?

Giorgio Brunello

Maria De Paola

October 2012

Forschungsinstitut zur Zukunft der Arbeit Institute for the Study of Labor 


\title{
Leadership at School: Does the Gender of Siblings Matter?
}

\author{
Giorgio Brunello \\ University of Padova, \\ CESifo, IZA and ROA
}

Maria De Paola

University of Calabria

\section{Discussion Paper No. 6976 \\ October 2012}

\author{
IZA \\ P.O. Box 7240 \\ 53072 Bonn \\ Germany \\ Phone: +49-228-3894-0 \\ Fax: +49-228-3894-180 \\ E-mail: iza@iza.org
}

Any opinions expressed here are those of the author(s) and not those of IZA. Research published in this series may include views on policy, but the institute itself takes no institutional policy positions. The IZA research network is committed to the IZA Guiding Principles of Research Integrity.

The Institute for the Study of Labor (IZA) in Bonn is a local and virtual international research center and a place of communication between science, politics and business. IZA is an independent nonprofit organization supported by Deutsche Post Foundation. The center is associated with the University of Bonn and offers a stimulating research environment through its international network, workshops and conferences, data service, project support, research visits and doctoral program. IZA engages in (i) original and internationally competitive research in all fields of labor economics, (ii) development of policy concepts, and (iii) dissemination of research results and concepts to the interested public.

IZA Discussion Papers often represent preliminary work and are circulated to encourage discussion. Citation of such a paper should account for its provisional character. A revised version may be available directly from the author. 
IZA Discussion Paper No. 6976

October 2012

\section{ABSTRACT \\ Leadership at School: Does the Gender of Siblings Matter? ${ }^{1}$}

Having leader positions at school, as well as participating in sports and clubs helps promoting valuable non cognitive skills, including leadership, self-discipline, motivation, competitiveness and self-esteem. We use survey data from the US and Japan to investigate whether these behaviors in middle and high school are affected by the gender composition of siblings. We find that having only sisters at age 15 increases substantially the probability of school leadership both for males and for females in the US and the probability of sport participation for males in Japan. We also find that parental education matters more for these behaviors in the US than in Japan, and that in the latter country the oldest son or daughter are more likely to be leaders in school.

JEL Classification: J24

Keywords: non-cognitive skills, school behaviors, siblings

Corresponding author:

Giorgio Brunello

Department of Economics

University of Padova

Via del Santo 33

35100 Padova

Italy

E-mail: giorgio.brunello@unipd.it

\footnotetext{
${ }^{1}$ This research uses micro data from the Preference Parameters Study of Osaka University's 21st Century COE Program 'Behavioral Macro-dynamics Based on Surveys and Experiments' and its Global COE project 'Human Behavior and Socioeconomic Dynamics'. We are grateful to Yukiko Abe, Francesca Gioia, Vincenzo Scoppa and Christoph Weiss for comments and to Yoshiro Tsutsui, Fumio Ohtake, and Shinsuke Ikeda for providing the data.
} 


\section{Introduction}

A growing body of empirical research shows that non-cognitive skills - including leadership, self-discipline, motivation, competitiveness and self-esteem - have a strong impact on educational attainment and labor market outcomes (Heckman and Rubinstein, 2001; Heckman et al. 2006). Recent evidence suggests that non-cognitive skills can be fostered by participating in extracurricular activities in middle or high school, such as holding leadership positions (being a team captain or a class officer) and being involved in sports or club activities. These activities help to instill self-discipline, motivation, competitiveness and selfesteem (Darling et al., 2005). The positive effect of participation in these activities on the development of valuable non-cognitive skills may also explain why high school leadership and sport involvement are associated with higher education and better academic performance (Barron et al., 2000; Rouse, 2008).

Another well established fact is that females tend to be more risk averse, less competitive and more altruistic than males. There is also evidence of a strong gender gap in the willingness to behave as a leader and in sport and club participation (see Ertac and Gurdal, 2012). This gap is likely to depend both on social interactions and on genetics. Beaman et al. (2012) use the Indian practice of reserving leadership positions to women in randomly selected village councils to show that female leadership positively affects the career aspirations and educational attainment of adolescent girls. Booth and Nolen (2012) use an experimental setup to examine whether single-sex environments affect the risk preferences of students and find that girls from single-sex schools are less risk averse than girls from mixedsex schools. They also find that girls are more likely to choose risky outcomes when assigned to all-girls experimental groups.

If the gendered aspects of individual behavior are brought into play by the gender of others with whom they interact, we expect the gender composition of siblings in the family to play an important role in the development of valuable non-cognitive skills. To illustrate, a girl who only interacts with sisters will not experiment the different attitudes that parents may reserve to sons and daughters, for instance by asking them to spend different amounts of time on household chores. On the one hand, being less exposed to stereotyped behaviors, females growing up in a whole-sisters family may be less inclined to acquire traditional gender roles. 
On the other hand, the interaction between sisters and brothers could produce relevant externalities, with females learning to male-behave from brothers and brothers learning female attitudes from their sisters.

In this paper we use rather unique survey data to investigate whether the gender composition of siblings at age 15 contributes to explaining school leadership and individual participation in extracurricular activities in secondary school. These data are from the "Preferences Parameters Study", conducted by Osaka University both in the US and in Japan, which contains information on individual participation in leadership positions, sports and clubs in middle and high school and on the gender composition of siblings at age 15.

We find that having only sisters at age 15 increases substantially the probability of school leadership both for males and for females in the US, and the probability of sport participation for males in Japan. In the US, leadership in school depends also on parental education, especially for males. In Japan, leadership increases with household wealth at age 15, with whether the individual was the oldest brother or daughter, and with perceived relative height. We speculate that one reason why the gender composition of siblings is less important for school leadership in Japan than in the US is that young Japanese spend a substantially higher share of their time in school than young Americans. Because of this, their interactions with schoolmates may be more important than those with siblings.

The paper is organized as follows. Section 2 describes the data. Section 3 discusses our main results and Section 4 concludes.

\section{Data}

Our data source is the "Preferences Parameters Study (PPS)", a household survey conducted on a yearly basis by Osaka University. The purpose of this survey is to collect information on individual preferences and behavior to verify whether the premise in economics that people act rationally to maximize utility has empirical support. Compared to other data-sets that provide information on individual preferences, such as the US Health and Retirement Study or the US Panel Study for Income Dynamics, this survey has also information on the gender composition of siblings when the interviewed individual was 15 years old. 
While in the US the survey is administered by mail to the US My Survey panel, a nonrepresentative sample of consumers who have voluntarily joined the panel to participate to consumer surveys, in Japan the survey is carried out by interviewers, who visit the households selected by a two-stage stratified random sample. Since the US sample is non-representative, it is useful to compare its main characteristics to those of the March Current Population Survey (CPS) sample. Focusing on 2007, we find that in the former sample the proportion of females is slightly higher than in the latter (52.2 versus 51.8), and that the distribution by education is heavily skewed toward those with at least a college degree, who are $49.6 \%$ in the PPS and $27.2 \%$ in the CPS $^{2}$.

We use the 2007 wave in either country because it contains the same questions on leadership and extracurricular activities in secondary school as well as information on siblings at age 15. We retain only individuals aged between 20 and 65 and obtain a final sample of 1497 individuals in the US and 2450 individuals in Japan. In the US, 19.6 percent of the selected sample had only sisters at 15, 22.7 percent had only brothers, 44 percent had both brothers and sisters and 12.7 percent were single children. In Japan, 27.3 percent of the selected sample had only sisters, 31.1 percent had only brothers, 36.6 percent had both brothers and sisters and only 4 percent were single children.

We define leadership as a dummy equal to one if the interviewed individual was class president, captain of a sport team or a club or student council member in middle or high school, and to zero otherwise. The percentage of those who had a leadership position in middle or high school turns out to be much higher in Japan (43.6 percent) than in the US (20.1 percent). As expected, in both countries college graduates are more likely to have been leaders (19.5 percent in the US and 56.7 percent in Japan ) than those without a college degree (13.3 percent in the US and 38.7 percent in Japan).

The survey measures participation in sport and other clubs with the following question: "Were you involved in any school club activities in middle school or high school? If you were in more than one club, answer for the one you had put in the most effort”. Individuals could choose one among the following answers: a) I actively participated in a sports team; b) I somewhat participated in a sports team; c) I actively participated in a club other than sports

\footnotetext{
${ }^{2}$ Further details on the design of the PPS survey are available at the website http://www.iser.osakau.ac.jp/coe/data-e/data.html.
} 
team; d) I somewhat participated in a club other than sports team; e) I did not participate in any sports team or club activities.

We define the dummy variable Sport as equal to one if the individual chooses options a) or b) and to zero otherwise, and the dummy Club as equal to one if the individual selects c) and d), and to zero otherwise. The percentage of individuals who engaged in sport activities in middle and high school was 30.6 in the US and 60 percent in Japan, and the percentage enrolled in a club was 34.2 percent in the US and 34.6 percent in Japan.

\section{Results}

We regress the three measures of extracurricular activities on three dummies capturing the gender composition of siblings in the household at age 15 - only sisters, only brothers, neither brother nor sister - and on the following additional covariates: a dummy equal to one if the individual is the oldest brother or sister and to zero otherwise; the number of siblings in the house at age 15; a dummy indicating whether the individual was taller than average at age 15; a dummy equal to one if either parent had at least some college education and to zero otherwise; a categorical indicator of household wealth at age 15 (ranging from 0 for poorest to 10 for wealthiest), a set of age cohort dummies - which capture the different periods when interviewed individuals were in secondary school - and a dummy for residence at age 15 in Southern states for the US and in metropolitan areas for Japan. Our estimates are reported in Table 1 for the US and in Table 2 for Japan.

Consider first leadership (columns (1) and (2) in each table). In the case of the US, we find that having only sisters as siblings increases the probability of being a leader at school by 13 percentage points for males and by 18 percentage points for females with respect to having both brothers and sisters (the baseline). Given that the percentage of individuals with leadership in secondary school is close to 20 percent, these are very large effects ${ }^{3}$. In the case of females, having only brothers can also increase leadership with respect to having both brothers and sisters, although to a much lesser extent than in the case of having only sisters. There is also evidence that better parental education increases leadership in the case of males, and affects also participation in clubs and sports.

\footnotetext{
${ }^{3}$ In our sample, the number of siblings ranges from 0 to 5 . Our results hold also when we restrict the sample to individuals with at most two siblings or to individuals aged 20 to 45 (results available from the authors upon request).
} 
In contrast with US results, the gender composition of siblings does not have statistically significant effects on school leadership in Japan ${ }^{4}$. In this country, having only sisters generally does not matter, with the exception of male participation in sports, where it increases participation by 8.5 percentage points with respect to having both brothers and sisters. Compared to the US, where they do not have statistically significant effects, being the oldest brother or sister, or being taller than average, or having relatively high household wealth at 15 matter more for leadership in school than the gender composition of siblings.

\section{Concluding remarks}

Kuhn and Weinberger, 2005, have shown that individuals who had leadership positions in high school earn between 4 and 24 percent higher wages 10 years later. Barron and coauthors, 2000, have found that athletic participation in school affect wages later on. Although leadership is an important "soft skill”, economists know very little about how it is acquired. An obvious candidate is parental background. Dhuey and Lipscomb, 2008, show that an additional factor is the child's relative age among her cohort.

While Booth and Nolen, 2012, have focused on the gender composition of schoolmates (single-sex schools versus mixed-sex schools) as a shaper of non-cognitive skills, in this paper we have considered instead the social interactions within the household and highlighted the potential importance of the gender composition of siblings. Our evidence from countries as different as the US and Japan shows that gender composition matters in the former country but not in the latter.

We have found that that having only sisters at age 15 in the US increases substantially the probability that both males and females take up leader positions at school, even after controlling for parental education. We speculate that, being less exposed to stereotyped behaviors, females growing up in a whole-sisters family may be less inclined to acquire traditional gender roles, and therefore more willing to take up leadership position at school. On the other hand, males growing up in a whole-sisters family may be more inclined to take up traditional gender roles. If leadership is a male prerogative, they are likely to exercise this prerogative to a higher extent at school.

\footnotetext{
${ }^{4}$ Having only brothers reduces the likelihood of having a leadership position in school among Japanese males. This effect, however, is statistically significant only at the 10 percent level of confidence.
} 
We believe that a candidate reason why the gender composition of siblings matters less for school leadership in Japan than in the US is the longer time that Japanese secondary school students spend in schools. According to Juster and Stafford, 1991, the average number of weekly hours spent at school in Japan was 46.6 in junior high schools and 41.5 in high schools. In contrast, time spent at school was much shorter in the US (28.7 in junior high and 26.2 in high school). Because of this longer time, social interactions with school mates in Japan may be more important than the interactions with siblings in shaping individual preferences and behaviors. 
Table 1. Participation in Extracurricular Activities at age 15. By gender. USA 2007. Marginal effects. Probit

\begin{tabular}{lccccccc}
\hline & $(1)$ & $(2)$ & $(3)$ & $(4)$ & $(5)$ & $(6)$ \\
& \multicolumn{2}{c}{ Leadership } & \multicolumn{2}{c}{ Club activity } & \multicolumn{2}{c}{ Sport activity } \\
Covariates & males & females & males & females & males & Females \\
\hline \multirow{3}{*}{ Only sisters } & & & & & & \\
& $0.129^{* *}$ & $0.179 * * *$ & 0.092 & 0.058 & -0.026 & 0.111 \\
Only brothers & $(0.057)$ & $(0.068)$ & $(0.067)$ & $(0.076)$ & $(0.069)$ & $(0.076)$ \\
& 0.069 & $0.096^{*}$ & 0.031 & 0.109 & 0.028 & 0.109 \\
No brothers or sisters & $(0.050)$ & $(0.060)$ & $(0.060)$ & $(0.073)$ & $(0.065)$ & $(0.072)$ \\
& -0.033 & 0.117 & -0.008 & 0.133 & -0.016 & $0.251^{* *}$ \\
& $(0.065)$ & $(0.097)$ & $(0.090)$ & $(0.111)$ & $(0.100)$ & $(0.117)$ \\
Oldest son or daughter & & & & & & \\
& -0.025 & -0.023 & 0.063 & 0.062 & $-0.100^{* *}$ & 0.063 \\
& $(0.033)$ & $(0.036)$ & $(0.046)$ & $(0.050)$ & $(0.049)$ & $(0.047)$ \\
Taller than average at 15 & & & & & & \\
& 0.035 & -0.005 & 0.015 & 0.049 & -0.021 & 0.083 \\
Number of siblings & $(0.033)$ & $(0.036)$ & $(0.040)$ & $(0.053)$ & $(0.045)$ & $(0.052)$ \\
& 0.001 & $0.029^{*}$ & -0.017 & 0.010 & 0.011 & $0.052^{* *}$ \\
Parents with some college & $(0.015)$ & $(0.016)$ & $(0.020)$ & $(0.023)$ & $(0.021)$ & $(0.021)$ \\
& $0.105^{* * *}$ & -0.015 & 0.061 & $0.135^{* * *}$ & $0.116^{* * *}$ & 0.058 \\
Household wealth at 15 & $(0.031)$ & $(0.031)$ & $(0.039)$ & $(0.044)$ & $(0.045)$ & $(0.040)$ \\
& 0.004 & -0.000 & -0.009 & 0.008 & 0.008 & $0.034^{* * *}$ \\
Observations & $(0.009)$ & $(0.007)$ & $(0.010)$ & $(0.011)$ & $(0.011)$ & $(0.010)$ \\
& & & & & & 617 & 613
\end{tabular}

Note: robust standard errors within parentheses. Each regression includes a constant, age cohort dummies and the dummy SOUTH for individuals living in the

Southern states at age 15 . One, two and three starts for statistical significance at 10, 5 and 1 percent level of confidence. 
Table 2. Participation in Extracurricular Activities at age 15. By gender. Japan 2007. Marginal effects. Probit model.

\begin{tabular}{lcccccc}
\hline & $(1)$ & $(2)$ & $(3)$ & $(4)$ & $(5)$ & $(6)$ \\
& \multicolumn{2}{c}{ Leadership } & \multicolumn{2}{c}{ Club activity } & \multicolumn{2}{c}{ Sport activity } \\
Covariates & Males & females & males & females & males & females \\
\hline \multirow{3}{*}{ Only sisters } & & & & & & \\
& -0.049 & -0.018 & 0.026 & -0.001 & $0.085^{* *}$ & -0.053 \\
Only brothers & $(0.047)$ & $(0.042)$ & $(0.041)$ & $(0.043)$ & $(0.036)$ & $(0.041)$ \\
& $-0.079^{*}$ & 0.004 & 0.012 & -0.018 & 0.034 & 0.013 \\
No brothers or sisters & $(0.046)$ & $(0.041)$ & $(0.040)$ & $(0.041)$ & $(0.037)$ & $(0.039)$ \\
& -0.055 & 0.078 & -0.025 & -0.110 & 0.047 & -0.108 \\
& $(0.097)$ & $(0.090)$ & $(0.078)$ & $(0.082)$ & $(0.073)$ & $(0.088)$ \\
Oldest son or daughter & & & & & & \\
& $0.062^{*}$ & $0.069^{* *}$ & -0.015 & 0.021 & 0.044 & -0.019 \\
Taller than average at 15 & $(0.035)$ & $(0.030)$ & $(0.028)$ & $(0.030)$ & $(0.029)$ & $(0.029)$ \\
Number of siblings & & & & & & \\
& $0.119^{* * *}$ & $0.084^{* * *}$ & -0.018 & -0.022 & 0.011 & 0.028 \\
Parents with some college & $(0.034)$ & $(0.030)$ & $(0.028)$ & $(0.029)$ & $(0.028)$ & $(0.028)$ \\
& -0.029 & -0.007 & -0.017 & $-0.059^{* * *}$ & 0.015 & 0.003 \\
Household wealth at 15 & $(0.019)$ & $(0.017)$ & $(0.015)$ & $(0.018)$ & $(0.015)$ & $(0.016)$ \\
& 0.006 & 0.014 & 0.013 & 0.025 & -0.054 & -0.007 \\
& $(0.037)$ & $(0.033)$ & $(0.031)$ & $(0.033)$ & $(0.033)$ & $(0.032)$ \\
Observations & $0.016^{*}$ & $0.031^{* * *}$ & 0.002 & -0.004 & 0.004 & -0.002 \\
& $(0.009)$ & $(0.008)$ & $(0.007)$ & $(0.008)$ & $(0.007)$ & $(0.007)$
\end{tabular}

Note: robust standard errors within parentheses. Each regression includes a constant, age cohort dummies and a dummy for residence at age 15 in a metropolitan area. One, two and three starts for statistical significance at 10, 5 and 1 percent level of confidence. 


\section{References}

Barron J., B. Ewing and G. Waddell (2000), "The Effects of High School Athletic Participation on Education and Labor Market Outcomes", Review of Economics and Statistics, 82(3), pp. 409-421.

Beaman L., E. Duflo, R. Pande and P. Topalova (2012), Female Leadership Raises Aspirations and Educational Attainment for Girls: A Policy Experiment in India, Science, 3, pp. 582-586.

Booth A. and Nolen P., (2012), Gender Differences in Risk Behaviour: does Nurture Matter? The Economic Journal, F56-F78.

Dhuey E. and S. Lipscomb, (2008), What makes a leader? Relative age and high school leadership, Economics of Education Review, 27, pp. 173-183.

Darling, N., L. Caldwell and R. Smith, (2005), "Participation in school-based extracurricular activities and adolescent adjustment", Journal of Leisure Research, 37(1), pp. 51-76.

Ertac S. and M. Y. Gurdal, (2012), Deciding to decide: Gender, leadership and risk-taking in groups, Journal of Economic Behavior \& Organization, 3, pp. 24-30.

Heckman J. and Y. Rubinstein (2001), The Importance of Noncognitive Skills: Lessons from the GED Testing Program, American Economic Review, 91(2), pp. 145-149.

Heckman J., Stixrud, J., Urzua, S. (2006), The Effects of Cognitive and Noncognitive Abilities on Labor Market Outcomes and Social Behavior, Journal of Labor Economics, 24(3), pp. 411-482.

Kuhn. P. and Weinberger, C. (2005), Leadership Skills and Wages, Journal of Labor Economics, 23(3), pp. 395-436.

Juster F and Stafford F, (1991), The Allocation of Time: Empirical Findings, Behavioral Models and Problems of Measurement, Journal of Economic Literature, 471-522.

Rouse K., (2008) The Impact of High School Leadership on Subsequent Educational Attainment, mimeo 